\title{
Functional patterns of tree communities in natural Araucaria forests and old monoculture conifer plantations
}

\author{
Marcelo Malysz ${ }^{1 *}$ (D), Sandra Cristina Müller ${ }^{2}$ (D) , Silvia Vendruscolo Milesi ${ }^{3}\left(\mathbb{D}\right.$, Anita Stival dos Santos $^{1}$ \\ and Gerhard Ernst Overbeck ${ }^{1,4}$ (I)
}

Received: July 17, 2019

Accepted: November 2, 2019

\begin{abstract}
A functional perspective of tree communities is helpful for understanding forest dynamics, especially vegetation recovery after other land uses. Knowledge about ecological filters and survival strategies of trees are also important for the restoration of degraded areas. This study aimed to evaluate the functional composition and structure of adult and regenerative components of natural Araucaria forests, Araucaria plantations and plantations of exotic Pinus in subtropical southern Brazil. Differences in functional diversity and functional richness, and in community weighted mean trait values, including leaf traits and reproductive traits, were analyzed. RLQ analysis was used to assess the association between community structure, plant traits and environmental variables. Clear differences were found for most traits and for functional richness for the regenerative component, while the adult component was more similar among forest types. A clear separation in RLQ ordination associated with trait variation, for the adult component but not for regenerative trees, also indicates that communities are becoming functionally more similar with time. Plantations were shown to function as environmental filters by directly influencing species recruitment, richness and functional diversity. We conclude that passive restoration may be the best strategy for restoration of Araucaria forests.
\end{abstract}

Keywords: Araucaria angustifolia, Atlantic Forest, forest dynamics, functional diversity, functional patterns, Pinus sp., succession, tree plantations

\section{Introduction}

Functional characteristics are important to understand the relationship between plant species and the environmental factors that influence their performance and dynamics (e.g. Díaz \& Cabido 2001; Díaz et al. 2016). The functional characteristics of a forest community can help to explain the coexistence of species in space and time, and the range of plant functional traits indicates the ecological advantages of different plant strategies to different environmental conditions (Wright 2002; Westoby
\& Wright 2006). Changes in land use, such as conversion of natural vegetation into plantations, result in clear changes of composition, dynamics and processes of ecosystems in response to changed or new environmental filters, at both the site and the landscape scale (e.g. Garnier et al. 2007; Laliberté et al. 2009). These changes can alter abundances of certain species or modify considerably the functional structure of the entire community (Raevel et al. 2012). Changes may have long lasting effects, affecting natural regeneration of such communities for decades. Information on community functional composition can thus improve our ability to understand and forecast the dynamics of

1 Programa de Pós-Graduação em Botânica, Universidade Federal do Rio Grande do Sul, 91501-970, Porto Alegre, RS, Brazil

2 Departamento de Ecologia, Programa de Pós-Graduação em Ecologia, Universidade Federal do Rio Grande do Sul, 91501-970, Porto Alegre, RS, Brazil

3 Departamento de Ciência Biológicas, Universidade Regional Integrada do Alto Uruguai e das Missões, 99709-910, Erechim, RS, Brazil

4 Departamento de Botânica, Universidade Federal do Rio Grande do Sul, 91501-970, Porto Alegre, RS, Brazil

* Corresponding author: mmalysz@gmail.com 
succession, and from an applied perspective, help to select appropriate strategies to manage these changes.

To evaluate the recovery potential of degraded areas from a functional perspective at the community level, plant traits related to dispersal and establishment (Cramer et al. 2008) and traits related to growth under stressful environmental conditions (e.g. Funk et al. 2008) are especially relevant. They can indicate factors that limit or promote the recovery of vegetation by succession, or the restoration of the affected plant communities (Weiher et al. 1998; Asanok et al. 2013), for example, when evaluating regeneration patterns. In addition to the analysis of specific traits, synthetic measures, as functional indices and functional composition (i.e. community weighted mean of traits - CWM), are helpful to indicate overall patterns of the community and ecosystem level functioning (Diáz et al. 2007). Functional diversity, among other indices (Mason et al. 2007), is used to quantify the distribution of a set of traits within the community (Mouillot et al. 2005). Functional diversity can also help to understand species coexistence, as species are subjected to the action of environmental filters that narrow the establishment of functional characteristics in space and time within a community (Zobel 1997; Mason et al. 2007).

The invasion or introduction of alien species can lead communities and ecosystems to differ considerably from their natural counterparts, not only in species composition, but also concerning their functionality (Foley et al. 2005; Parton et al. 2007; Cornwell et al. 2008). Tree plantations with exotic species are an example of this, especially when in form of monocultures. In southeastern South America, mostly pine and eucalypt tree plantations have increased considerably in the past two decades, which makes the evaluation of their effects on plant and animal communities inside the plantations and in their surroundings an important issue (e.g. Zurita et al. 2006; Fischer et al. 2014). Moreover, transformation of monocultures into natural forests can be an important conservation and restoration strategy (Mendonça-Lima et al. 2014). However, only few studies evaluate the potential of this transformation (e.g. Mendonça-Lima et al. 2014; Podadera et al. 2015) and the successional processes that may ultimately lead to the establishment of near-natural forests are not well understood.

Brazil's Araucaria Forest, a subtropical forest formation, with the conspicuous conifer tree Araucaria angustifolia (considered as threatened, in category 'vulnerable' in Rio Grande do Sul, according to Decreto 52.109 from $19 / 01 / 2014$, and in category 'endangered' in Brazil, according to Portaria MMA 443 de 17/12/2014) in the upper layer of a subtropical broadleaf forest, is part of Brazil's Atlantic Forest biome. The formation is restricted to the highland region of larger parts of southern and smaller parts of southeastern Brazil, and today presents only about $1 \%$ of its original area (Medeiros et al. 2005). The main factor responsible for this reduction was the extensive clearcutting in the past, in order to get land for agriculture and livestock (Sanquetta \& Mattel 2006). As pointed out by Jarenkow \& Budke (2009), the establishment of large energy projects in the form of dams and roads are factors that today continue to threaten the integrity of the remaining patches of Araucaria Forest. Therefore, studies aiming the conservation and restoration of this forest are of high importance.

This study aims to evaluate the functional composition and structure of the regenerative and adult component of three different forest types: natural Araucaria Forest stands, abandoned plantations of Araucaria and abandoned Pinus plantations. We wish to elucidate successional processes from a functional perspective. In the plantations, established some 60 years ago, spontaneous establishment processes have been taking place during the past 30 years, and a previous study (Malysz \& Overbeck 2018) showed much lower recruitment of tree individuals in the plantations than in the natural forests, as well as lower soil fertility in plantations. More specifically, we aimed to answer the following questions: (1) How does the functional structure (diversity and composition) of the tree community differ between natural forests and both types of plantations? (2) Which environmental factors better explain variation between stands? We hypothesized: (1) Lower soil organic matter and lower soil nutrient content in pine plantations should act as a filter for regeneration, reducing functional diversity and richness; (2) Regeneration within the pine plantation should depend on pioneer species with light and easily dispersed seeds; (3) No or lower differences in regeneration patterns should exist between Araucaria plantations and the native forest, due to high contribution of Araucaria angustifolia itself in both types of communities, an thus predominance of species with heavy, animal-dispersed seeds. Altogether, we expected that differences should be stronger for the adult component when compared to the regenerative component, as tree recruitment in the plantations and other successional processes after abandonment of management should slowly contribute to higher similarity among forest types.

\section{Materials and methods}

\section{Study area}

Our study was conducted in the Passo Fundo National Forest (FLONA Passo Fundo), located in the north of Rio Grande do Sul state, Brazil, in Mato Castelhano municipality (28 $\left.16^{\prime} 44^{\prime \prime}-28^{\circ} 20^{\prime} 40^{\prime \prime} \mathrm{S} 52^{\circ} 09^{\prime} 59^{\prime \prime}-52^{\circ} 12^{\prime} 35^{\prime \prime} \mathrm{W}\right)$. This protected area has a total area of 1358 ha, of which 365.4 ha are native well-preserved forest (Araucaria forest, characterized by the dominant species Araucaria angustifolia and the co-occurrence of many broadleaf species), 391 ha are abandoned plantations of Araucaria angustifolia in monoculture, 278 ha are abandoned plantations of Pinus 
spp. in monoculture, and 331 ha have other types of cover (ICMBio 2014). Plantations were established in 1947 and managed for 35 years, and since then they are under natural succession without any management interventions. In the following, we refer to the three communities as three distinct forest types: natural forest and the respective Araucaria and Pinus Plantations. The three types form an irregular mosaic of forest stands, with stand size ranging from 10 to 60 ha. Soils in the region are loamy, well-drained and deep. In a previous study (Malysz \& Overbeck 2018) we described principal differences among the forest types regarding soil features (Tab. 1).

\section{Study design and vegetation sampling}

Five stands were randomly chosen for each forest type, distributed throughout the entire area. In each of these forest stands, we established 10 sampling units (SU) of 10 by $10 \mathrm{~m}$, situated at least $20 \mathrm{~m}$ from the edge of the forest stand. For the adult component, all living tree individuals with a perimeter at breast height $(\mathrm{PBH}=1.3 \mathrm{~m}$ above ground) $\geq 15 \mathrm{~cm}$ within each $\mathrm{SU}$ were sampled. The survey of the regenerative tree component was performed in sub-plots of $5 \times 5 \mathrm{~m}$ within each SU, and all living tree individuals with height $\geq 30 \mathrm{~cm}$ and $\mathrm{PBH}<15 \mathrm{~cm}$ were sampled. Individuals with more than one stem were included in the sample when the sum of the basal areas of stems corresponded to the minimum PBH adopted. All sampled individuals were identified to the species level. Species richness was significantly higher in the natural forests that in the plantations for both components; additionally, number of individuals was significantly higher in natural forest for the regenerative component (Malysz \& Overbeck 2018). A detailed presentation of the structural characteristics of the tree communities and of the most important species can be found in Malysz \& Overbeck (2018).

We selected 10 traits (Tab. 2) that represent key processes of plant strategies in relation to competitive ability, dispersal, resource exploration and response to disturbances (Cornelissen et al. 2003). Leaf traits were obtained from our field measurements or from the database of the Plant Ecology Lab of the Federal University of Rio Grande do Sul. In both cases, data collection and measures were performed according to standardized protocols (Cornelissen et al. 2003; Pérez-Harguindeguy et al. 2013). In general, we sampled 10 leaves or leaflets in the case of compound leaves (including petioles) of at least five adult individuals per species. These leaves were weighed fresh and dried $\left(60^{\circ} \mathrm{C}\right.$ for $\left.72 \mathrm{~h}\right)$, scanned and analyzed with the software ImageJ to obtain the leaf area (Schneider et al. 2012). With these measurements we calculated specific leaf area (SLA) and leaf dry matter content (LDMC). When possible, we collected at least 10 mature seeds, which were oven-dried for $48 \mathrm{~h}$ at $80^{\circ} \mathrm{C}$ and then weighted in order to calculate seed mass. For those species that were not seeding, the seed mass data, as well as others traits, was taken from the literature. In total, we considered 59 species in the regenerative component and 34 species in the adult component.

Table 1. Soil features and habitat characteristics of the three studied forest types (native forest, Araucaria plantation, pine plantation). Different letters indicate significant differences ( $\mathrm{p}<0.05$ ). Canopy trees refer to individuals with diameter at breast high $\geq 5 \mathrm{~cm}$. Mean of canopy openness was measured through hemispheric photographs and analyzed with 'Gap light analyzer' program. From Malysz \& Overbeck (2018).

\begin{tabular}{|c|c|c|c|c|c|c|c|}
\hline Forest type & Clay (\%) & pH & $P(\mathrm{mg} / \mathrm{dm} 3)$ & $\mathrm{K}(\mathrm{mg} / \mathrm{dm} 3)$ & Soil organic matter (\%) & Light availability (\%) & Canopy trees (\#) \\
\hline Araucaria plantation & 35.6 & $4.6 \mathrm{a}$ & $4 \mathrm{ab}$ & $72.4 \mathrm{~b}$ & $6.4 \mathrm{a}$ & 19.3 & 19.3 \\
\hline Natural Forest & 39.2 & $4.4 b$ & $4.8 \mathrm{a}$ & $100.6 a$ & $6.4 \mathrm{a}$ & 18.3 & 18.0 \\
\hline Pinus plantation & 43.6 & $4.4 b$ & $3.5 c$ & $74.4 \mathrm{~b}$ & $4.8 b$ & 21.1 & 21.1 \\
\hline
\end{tabular}

Table 2. List of traits considered to each species and to further compare the functional structure of communities according to the three forest types.

\begin{tabular}{|c|c|c|}
\hline Trait (labels) & Measurements & Relation with plant performance * \\
\hline Leaf area (LA) & $\begin{array}{c}\text { Individual area of leaf or leaflets in compound } \\
\text { leaves }\left(\mathrm{mm}^{2}\right)\end{array}$ & Competitive ability \\
\hline Specific leaf area (SLA) & Area of a fresh leaf divided by its oven-dry mass $\left(\mathrm{m}^{2} \mathrm{~kg}^{-1}\right)$ & Competitive ability / Potential growth rate \\
\hline Leaf dry matter content (LDMC) & Oven-dry mass divided by its fresh mass $\left(\mathrm{mg} \mathrm{g}^{-1}\right)$ & Resource-use strategies \\
\hline Leaf thickness (LT) & Thickness of a laminar leaf $(\mathrm{mm})$ calculated by $1 /$ SLA*LDMC & Resource-use strategies \\
\hline Leaf nitrogen content (LNC) & Total amount of $\mathrm{N}$ per unit of dry leaf mass $\left(\mathrm{mg} \mathrm{g}^{-1}\right)$ & Growth and productivity \\
\hline Leaf phosphorus content (LPC) & Total amount of P per unit of dry leaf mass ( $\left.\mathrm{mg} \mathrm{g}^{-1}\right)$ & Growth and productivity \\
\hline Potential plant height $(\mathrm{He})$ & $\begin{array}{l}\text { Maximum height that plant may attain according } \\
\text { to the literature information (m) }\end{array}$ & Competitive ability (competition for light) \\
\hline Wood density (WD) & $\begin{array}{l}\text { Oven-dry mass of a stem section divided by the volume } \\
\text { of the same section fresh }\left(\mathrm{g} / \mathrm{cm}^{3}\right)\end{array}$ & Growth and resistance \\
\hline Seed mass (SM) & Oven-dry mass of an average seed of a species (g) & Dispersal ability and establishment \\
\hline Zoochory (Zo) & $\begin{array}{l}\text { Main mode of dispersal of the propagule. } \\
\text { Categories: zoochory (1), without zoochory (0) }\end{array}$ & Dispersal ability \\
\hline
\end{tabular}

* according to Cornelissen et al. (2003) and Pérez-Harguindeguy et al. (2013). 


\section{Data analyses}

Based on the species trait matrix and on the species density matrix, we calculated two functional diversity indices: Rao's quadratic entropy (Rao 1982) and the functional richness (Fric). Rao's quadratic entropy expresses the community trait diversity as the sum of the dissimilarities among all possible pairs of species in the trait space weighted by the product of species relative abundances. The functional richness (Fric) is a complementary component of trait diversity, which represents the amount of trait space filled by a community (Villéger et al. 2008). It is expressed as the smallest convex set (or minimum convex hull) enclosing the volume of the $\mathrm{n}$-dimensional trait space occupied by the species in a community (Cornwell et al. 2006). We compared values of functional diversity (Rao) and richness (Fric) between forest types (natural forest and the two types of plantation) by ANOVA (one way) and Tukey post-hoc tests to detect differences between treatments.

Community-weighted mean (CWM) trait values indicat the mean of each trait weighted by the relative abundance of the species in the community and thus can inform dominant traits in the community (Lavorel et al. 2008), which can be related to the mass ratio hypothesis (Grime 1998). Each sampling unit is here considered as the operational community. We compared the three forest types regarding CWM of each trait, by using ANOVA and post-hoc test (Tukey).

To understand the association of community structure with environmental variables and biotic factors we applied RLQ analysis, which is a fourth corner method that uses ordination analyses to relate environmental characteristics and species traits (Doledec et al. 1996; Dray et al. 2002; Dray \& Legendre 2008; Braak et al. 2012). Here, additionally to the species trait matrix (matrix $Q$ ) and the species abundance per community (matrix L), we considered an environmental matrix (matrix $\mathrm{R}$ ). In our case the matrix $\mathrm{R}$ consisted of soil variables (percentage of clay and organic matter, $\mathrm{pH}$, phosphorus, potassium, aluminum, calcium and magnesium content) and a measure of light availability (canopy openness). Data normality are verified using the Shapiro-Wilk test when necessary. All analyzes were performed with R software (R Development Core Team 2018), using packages FD and ade4.

\section{Results}

Functional richness showed significant differences between the native forest and the two plantation forests (Pinus and Araucaria) for the adult component. Natural Araucaria forest showed the highest values, while the plantations did not differ between each other (Fig. 1). In relation to functional diversity, forest types differed significantly from each other only for the regenerative component.

Comparing CWM values for individual traits of the three forest types, we found significant differences between the communities, particularly in respect to the adult component (Tab. 3 and Figs. S1, S2 in supplementary material). Differences concerned leaf traits (SLA, LT, LNC, LPC), reproductive trait (seed mass) and traits related to competitive ability and growth (WD and potential height) (Tab. 1 and Fig. S1 in supplementary material).

The RLQ of the regenerative component indicates the separation of the different forest types, but with some overlap of native forest and Araucaria plantation (Fig. 2A). In this stratum, differentiation of areas in terms of species composition was not strong, but differences in terms of trait values, soil parameters and incidence of light were clear (Fig. 2A, C, E).

The RLQ of the adult component indicates a clear separation of forest types, explained almost completely by the first two axes (Eigenvalues 0.73 and 0.06 ). The native forest is characterized by secondary and late-successional species, with higher SLA and WD values, and soils with higher phosphorus and potassium content. Araucaria plantations are characterized by high abundance of Araucaria itself - quite obvious - as well as by other species with larger seeds dispersed by animals, and by soils with higher organic matter. Pinus plantations are characterized by the increased presence of pioneer species with large leaves, higher LNC and LPC content, with autochoric and anemochoric dispersal (including pine itself), and more clayey soils with higher aluminum content (Fig. 2B, D, F).

\section{Discussion}

The general aim of this study was to elucidate functional patterns of natural forest and abandoned tree plantations in subtropical southern Brazil. In our study area, spontaneous succession in Araucaria and Pinus monocultures could take place for a period of almost 35 years since abandonment of management. The analysis of functional traits in succession research has repeatedly been pointed out as useful to assess the impacts of community changes on ecosystem properties (Garnier et al. 2004; Lavorel et al. 1999). Here, we consider the use of traits to be useful as they help to understand dispersal (Kraft et al. 2008) and recruitment patterns related to plant strategies (Reich et al. 2003). The separate analysis for the adult and regenerative components allowed us to consider temporal aspects of succession, even though admittedly in a rather coarse way. Regarding the design and conditions of our study (all three forest types were situated in a mosaic of stands with area between 10 and 60 ha each), we can expect that other factors that have been shown to influence tree recruitment in plantations, such as distance from source area (Martin-Queller et al. 2013), plantation age (Brockerhoff et al. 2003) and strong soil differences prior to planting (Wang et al. 2012) should not be of high importance, and we can thus evaluate effects of the plantings as such. Our results contribute to a better understanding of community and successional dynamics. 
They are also relevant for the development of restoration and management strategies that envision the transformation of tree plantations into more natural forest communities.

Although functional diversity did not present significant differences between the forest types in both strata, functional richness was significantly higher in the native forest. It has been shown before that differences in functional composition are not always accompanied by changes in functional diversity (Mandle \& Ticktin 2015): Functional richness and functional diversity indicate different aspects of the functional composition of plant communities (Mason et al. 2005). Functional diversity is the sum of similarities between the features of the species present in the community and considers species abundance.

A

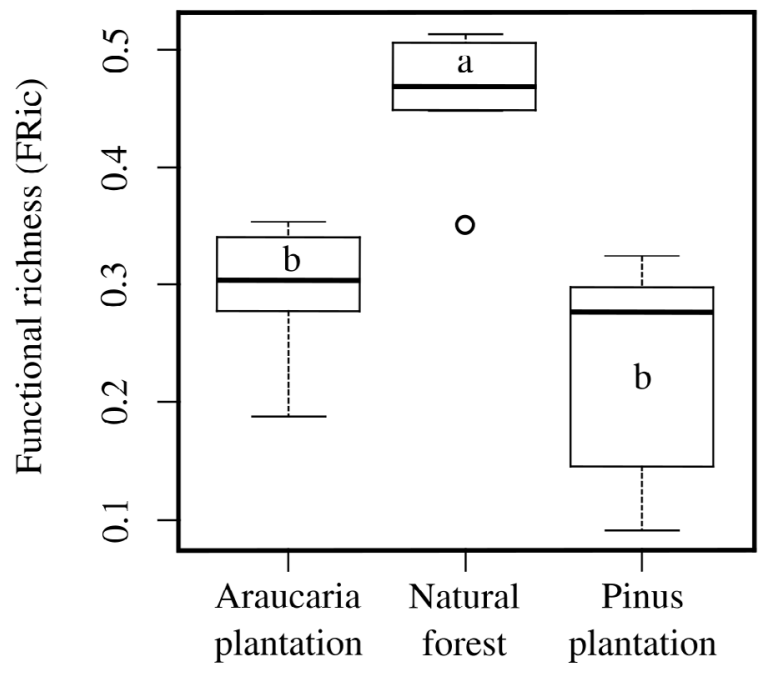

Forest type
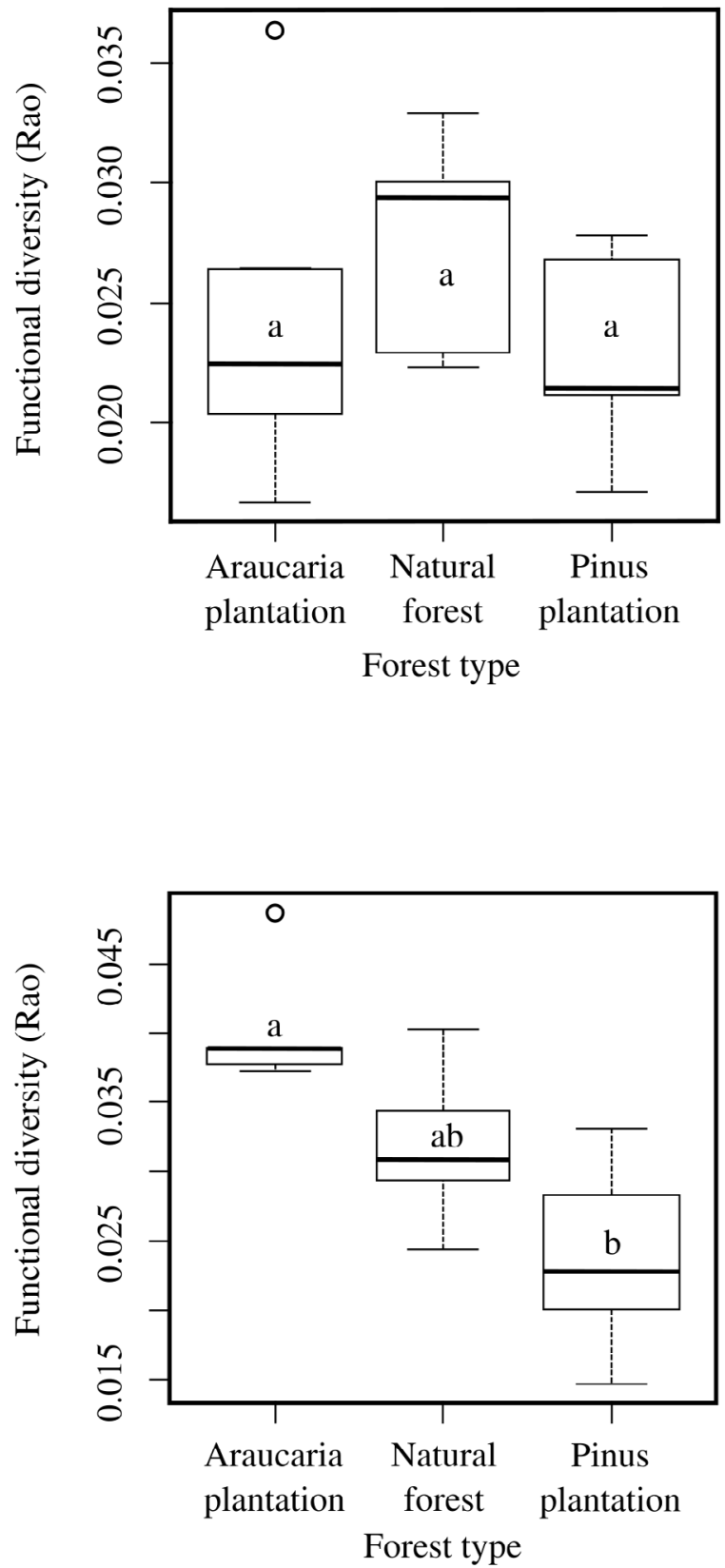

Figure 1. Boxplots showing the diversity and functional richness of regenerative component $(\mathbf{A})$ and adult component (B) for different forest type (native forest, Araucaria plantation and Pinus plantation). Thick lines in the center of the box indicate the median, the boxes indicate the first and third quartiles, and the whiskers represent the lowest datum within 1.5 IQR of the lower quartile, and the highest datum within 1.5 IQR of the upper quartile. Dots are outliers; Different letters indicated significant differences between forest types. 


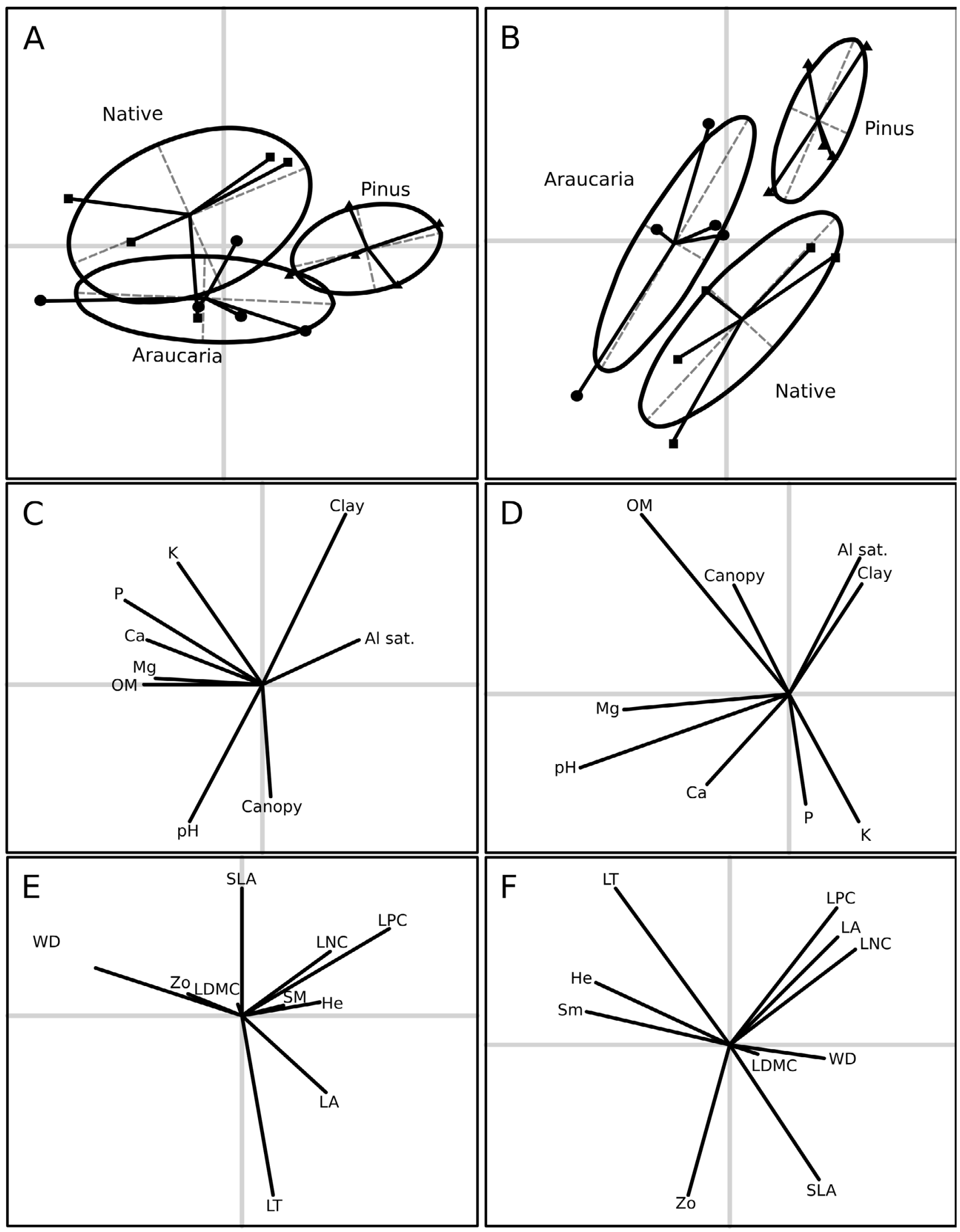

Figure 2. RLQ of the regenerative (A-C-E) and adult (B-D-F) components. In the analysis, R comprises environmental variables, $\mathrm{L}$ species abundance distribution matrix and $Q$ comprises the functional attributes of the species. A, D - mean position of species in the RLQ plan. B, E - environmental variables. C, F - functional traits. $\mathbf{\square}=$ Native forest; $\bullet=$ Araucaria plantation; $\boldsymbol{\Delta}=$ Pinus plantation. 
In contrast, functional richness concerns the number and the volume of traits in a community, being strongly associated to species richness (Cornwell et al. 2006; Villéger et al. 2008). The stronger differences in functional richness found for the adult component in our study indicate that environmental filtering within the plantations was stronger in the past than today. The regenerative component in the former plantation areas may already be a result of more suitable environmental conditions, e.g. as a consequence of the presence of a developing upper stratum. These consequences are less light and higher humidity, but also higher specific heterogeneity, which certainly contribute to increase the variability in traits of species that can colonize. Thus, considering the functional diversity, the regenerative stratum of native forests and Araucaria plantations did not differ anymore. However, differences in functional richness between them are still observed, which should be more related to species richness.

In our study, specifically the traits related to the leaf economic spectrum were useful to contrast the different tree communities of the adult component, reinforcing the importance of these traits in comparative plant ecology (Cornelissen et al. 2003; Díaz et al. 2016). When analyzing community weighted means of traits, we found considerable differences among adult tree communities, but not for the regenerative component. Adult communities in the Araucaria plantations showed differences in most of traits analyzed, when compared to the native forest and Pinus plantations. This indicates clearly that the different tree communities exerted different filtering roles in early successional stages, regarding both dispersal processes and plant strategies, with pioneer species - characterized by high LA, high SLA, low
LDMC, high concentrations of nitrogen and phosphorus (Cornelissen et al. 2003) - becoming established in higher abundances. However, for the regenerative component, i.e. individuals with a PBH below $15 \mathrm{~cm}$, Araucaria plantations presents differences to the other forest types, namely LT, SLA, LPC and LNC. This can be explained by the lower canopy openness of Araucaria plantation communities due to the intense densification of planted trees. Apparently, in our case, plantations served as environmental filters for tree recruitment in early phases of abandonment, while this effect became lower in later stages. The higher amount of leaf nitrogen found in the regenerative component of Pinus plantations indicates a greater growth capacity and productivity of the species present. This rate is directly and proportionally influenced by the incidence of light at the respective site, and leaf traits related to the fitness of the species (Cornelissen et al. 2003). The density of the wood also tended to show higher values in the areas of natural forest. This attribute indicates the allocation of individual biomass, increased strength and increased survival rate.

In contrast to the adult component, an overlap between the natural forest and Araucaria plantations was found for the regenerative component, indicating the higher similarity of younger communities than the older ones. Further, the analysis revealed relations between abiotic factors and functional attributes for the regenerative component, as hypothesized. The native forest showed a higher organic matter content than the plantations: this corresponds to previous findings on differences of soil properties between native forest and Pine plantations in other regions where lower $C$ content was found in the soils of plantations (Kasel $\&$ Benett 2007). Our analyses revealed a direct relation of

Table 3. Mean values of each community-weighted mean trait (CWM) of native forest and abandoned forest plantations (Pine and Araucaria) for regenerative (R) and adult (A) components. Different letters indicate significant differences between forest types (variables with significant differences among forest types in bold).

\begin{tabular}{|c|c|c|c|c|c|c|}
\hline Trait & Component & Araucaria Plantation & Natural Forest & Pine Plantation & $f$ & $\mathbf{p}$ \\
\hline \multirow[t]{2}{*}{ LA } & $\mathrm{R}$ & $15.88 \mathrm{a}$ & $14.04 \mathrm{a}$ & $18.51 \mathrm{a}$ & 1.74 & 0.217 \\
\hline & A & $9.93 \mathrm{~b}$ & 16.11 a & 18.08 a & 11.57 & 0.001 \\
\hline \multirow[t]{2}{*}{ SLA } & $\mathrm{R}$ & $13.34 \mathrm{~b}$ & 16.25 a & $13.75 \mathrm{~b}$ & 8.77 & 0.004 \\
\hline & A & $10.04 \mathrm{~b}$ & $14.61 \mathrm{a}$ & $13.61 \mathrm{a}$ & 26.2 & $<0.001$ \\
\hline \multirow[t]{2}{*}{ LDMC } & $\mathrm{R}$ & $398.16 \mathrm{a}$ & $384.10 \mathrm{a}$ & $401.43 \mathrm{a}$ & 3.35 & 0.069 \\
\hline & A & $398.67 \mathrm{a}$ & $399.64 \mathrm{a}$ & $398.41 \mathrm{a}$ & 0.01 & 0.984 \\
\hline \multirow[t]{2}{*}{ LT } & $\mathrm{R}$ & 0.27 a & $0.23 \mathrm{~b}$ & 0.24 b & 7.19 & 0.008 \\
\hline & A & 0.38 a & 0.24 b & $0.26 b$ & 42.86 & $<0.001$ \\
\hline \multirow[t]{2}{*}{ LNC } & $\mathrm{R}$ & $1.86 \mathrm{~b}$ & $1.97 \mathbf{a b}$ & $2.15 a$ & 7.01 & 0.009 \\
\hline & A & $1.42 \mathrm{~b}$ & 1.82 a & 1.92 a & 23.71 & $<0.001$ \\
\hline \multirow[t]{2}{*}{ LPC } & $\mathrm{R}$ & 0.14 b & 0.15 a & 0.15 a & 5.25 & 0.022 \\
\hline & A & $0.12 b$ & $0.14 a$ & 0.15 a & 13.21 & $<0.001$ \\
\hline \multirow[t]{2}{*}{$\mathrm{He}$} & $\mathrm{R}$ & $22.14 \mathrm{a}$ & $21.81 \mathrm{a}$ & $23.22 \mathrm{a}$ & 1.78 & 0.21 \\
\hline & A & 30.92 a & $24.45 \mathrm{~b}$ & $24.17 b$ & 41.17 & $<0.001$ \\
\hline \multirow[t]{2}{*}{ WD } & $\mathrm{R}$ & $0.66 \mathrm{a}$ & $0.68 \mathrm{a}$ & $0.64 \mathrm{a}$ & 2.82 & 0.098 \\
\hline & A & 0.58 b & $0.65 a$ & $0.65 a$ & 26.23 & $<0.001$ \\
\hline \multirow[t]{2}{*}{$\mathrm{Sm}$} & $\mathrm{R}$ & $0.46 \mathrm{a}$ & $0.45 \mathrm{a}$ & $0.34 \mathrm{a}$ & 0.63 & 0.549 \\
\hline & A & 2.70 a & 0.79 b & 0.54 b & 55.89 & $<0.001$ \\
\hline \multirow[t]{2}{*}{ Zo } & $\mathrm{R}$ & $0.91 \mathrm{a}$ & $0.83 \mathrm{a}$ & $0.87 \mathrm{a}$ & 1.72 & 0.22 \\
\hline & A & $0.96 \mathrm{a}$ & $0.91 \mathrm{a}$ & $0.92 \mathrm{a}$ & 2.29 & 0.144 \\
\hline
\end{tabular}


this factor to mean values of wood density, but an indirect relation with $\mathrm{P}$ and $\mathrm{N}$ leaf content regarding the species of the regenerative component, and thus indicating a preference of slow growing species and high strength. Light incidence has been shown to be an important factor influencing tree recruitment (Parrotta 1995). In our case, though, no significant differences were found among vegetation types. However, in earlier phases of the plantings, higher light incidence may have favored the establishment of pioneer species, since we can see some relation between higher canopy cover and higher leaf thickness for both community components. Aluminum concentration and percentage of clay in the soils were correlated with Pinus plantation and with high $\mathrm{P}$ and $\mathrm{N}$ content in the leaves of species. The aluminum concentration here observed seems not be affecting the presence of fast-growing species in the Pinus plantation sites, but other studies reported an association of this element to low SLA and high LDMC, indicating less investment in growing individuals (Scholes \& Nowicki 1998; Májeková et al. 2014).

As Araucaria is a native species of the region, and indeed a species that physiognomically dominates the forests, we had expected that Araucaria plantations would present higher overall similarity with the native forest than with the plantings of the exotic species, which was in fact observed. In the latter, the presence of the exotic species Hovenia dulcis, a species included in the official list of invasive plants in Rio Grande do Sul (SEMA 2013), and that has shown to have negative impacts on tree species composition (Lazzarin et al. 2015), is a clear sign of degradation. Apart from the direct effects of these plants in the community, in this case the regeneration in the Pine plantations, these sites are problematic as they serve as propagule sources for close-by communities (Zanchetta \& Diniz 2006). This species generates great impact in natural areas, changing not only the dominance but also the physiognomy of the communities, generating loss of natural diversity, as invasive species in general.

Nonetheless, just as found by Mendonça-Lima et al. (2014) and indicated in our own analysis of the floristic composition and vegetation structure, both types of plantations showed considerable recruitment of native species, and we can expect that the communities will get more similar over time. In the case of our study systems, we still may not be able to call them 'catalysts' for recovery of degraded areas (Mendonca-Lima et al. 2014), as they likely will not be helpful for the recovery of near-by sites - at least in the case of sites with the presence of Pinus. Dispersal of Pinus seeds to nearby areas should indeed remain a problem for long periods: as long as fruiting pine trees are present, non-forested areas in the vicinity will suffer from invasion by this exotic conifer. Seed rain from Araucaria, on the other hand, can be considered positive: Araucaria trees have been found to have an important role as perching structures for birds, and thus their establishment in degraded areas may in fact contribute to regeneration processes (Streit et al. 2014).

In conclusion, our study indicates that plantations act as environmental filters for tree recruitment when compared to native forest, causing stronger recruitment of pioneer species with certain functional characteristics and differences in functional diversity and richness. However, their effects become weaker over time as regenerative communities are already become more similar to native forests. Considering the propensity of Pine to establish easily in gaps with higher light availability, passive restoration, even though it will take decades, may be more successful, and of course much more low-cost, than felling and removal of Pine trees. Effects of the individual removal of Pinus trees, including on recruitment of Pine itself in gaps, or of alternative strategies, such as girdling, should be analyzed in experimental plots. Altogether, the functional approach used here was important in allowing for a deeper understanding of the filtering effect of the plantations as well as the successional processes under way.

\section{References}

Asanok L, Marod D, Duengkae P, et al. 2013. Relationships between functional traits and the ability of forest tree species to reestablish in secondary forest and enrichment plantations in the uplands of northern Thailand. Forest Ecology and Management 296: 9-23.

Braak C, Cormont A, Dray S. 2012. Improved testing of species traitsenvironment relationships in the fourth corner problem. Ecology 93: 1525-1526.

Brockerhoff EG, Ecroyd CE, Leckie AC, Kimberley MO. 2003 Diversity and succession of adventive and indigenous vascular understorey plants in Pinus radiata plantation forests in New Zealand. Forest Ecology and Management 185: 307-326.

Cornelissen JHC, Lavorel S, Garnier E, et al. 2003. A handbook of protocols for standardised and easy measurement of plant functional traits worldwide. Australian Journal of Botany 51: 335-380.

Cornwell WK, Cornelissen JHC, Amatangelo K, et al. 2008. Plant species traits are the predominant control on litter decomposition rates within biomes worldwide. Ecology Letters 11: 1065-1071.

Cornwell WK, Schwilk DW, Ackerly DD. 2006. A trait-based test for habitat filtering: convex hull volume. Ecology 87: 1465-1471.

Cramer VA, Hobbs RJ, Standish RJ. 2008. What's new about old fields? Land abandonment and ecology assembly. Trends in Ecology \& Evolution 23: 104-112.

Díaz S, Cabido M. 2001 Vive la difference: plant functional diversity matters to ecosystem processes. Trends in Ecology \& Evolution 16: 646-655.

Díaz S, Kattge J, Cornelissen JHC, Wright IJ, et al. 2016. The global spectrum of plant form and function. Nature 529: 167-171.

Díaz S, Lavorel S, Bello F, Quetier F, Grigulis K, Robson M. 2007. Incorporating plant functional diversity effects in ecosystem service assessments. Proceedings of the National Academy of Sciences of the United States of America 104: 20684-20689.

Doledec S, Chessel D, Braak CJF, Champely S. 1996. Matching species traits to environmental variables: a new three-table ordination method. Environmental and Ecological Statistics 3: 143-166.

Dray S, Legendre P. 2008. Testing the species traits-environment relationships: the fourth-corner problem revisited. Ecology 89: 3400-3412.

Dray S, Pettorelli N, Chessel D. 2002. Matching data sets from two different spatial samplings. Journal of Vegetation Science 13: 867-874.

Fischer FM, Oliveira JM, Dresseno ALP, Pillar VD. 2014. The role of invasive pine on changes of plant composition and functional traits in a costal dune ecosystem. Natureza \& Conservação 12: 19-23. 
Foley JA, DeFries R, Asner GP, et al. 2005. Global consequences of land use. Science 309: 570-574.

Funk JL, Cleland EE, Suding KN, Zavaleta EZ. 2008. Restoration through reassembly: plant traits and invasion resistance. Trends in Ecology \& Evolution 23: 695-703.

Garnier E, Cortez J, Billès G, et al. 2004. Plant functional markers capture ecosystem properties during secondary succession. Ecology 85: 2630-2637.

Garnier E, Lavorel S, Ansquer P, et al. 2007. A standardized methodology to assess the effects of land use change on plant traits, communities and ecosystem functioning in grasslands. Annals of Botany 99: 967-985.

Grime JP. 1998. Benefits of plant diversity to ecosystems: immediate, filter and founder effects. Journal of Ecology 86: 902-910.

ICMBio - Instituto Chico Mendes de Conservação da Biodiversidade. 2014. Dados sobre a Floresta Nacional de Passo Fundo. http://www.icmbio. gov.br/portal/flona-de-passo-fundo. 27 Nov. 2014.

Jarenkow JA, Budke JC. 2009. Padrões florísticos e análise estrutural de remanescentes de Florestas com Araucária no Brasil. In: Fonseca $C R$, Souza AF, Leal-Zanchet AM, Dutra T, Backes A, Ganade G. (Orgs.) Floresta com araucária: ecologia, conservação e desenvolvimento sustentável. Ribeirão Preto, Holos. p. 113-126.

Kasel S, Bennet LT. 2007. Land-use history, forest conversion, and soil organic carbon in pine plantations and native forests of south eastern Australia. Geoderma 137: 401-413.

Kraft NJB, Valencia R, Ackerly DD. 2008. Functional traits and nichebased tree community assembly in an Amazonian Forest. Science 322: 580-582.

Laliberté E, Wells JA, DeClerck F, et al. 2009. Land-use intensification reduces functional redundancy and response diversity in plant communities. Ecology Letters 13: 76-86.

Lavorel S, Rochette C, Lebreton JD. 1999. Functional groups for response to disturbance in Mediterranean old fields. Oikos 84: 480-498.

Lavorel S, Grigulis K, McIntyre S, et al. 2008. Assessing functional diversity in the field - methodology matters! Functional Ecology 22: 134-147.

Lazzarin LC, Silva AC, Higuchi P, Souza K, Perin JE, Cruz AP. 2015. Invasão biológica por Hovenia dulcis THUNB. Em fragmentos florestais na região do Alto Uruguai, Brasil. Revista Árvore 39: 1007-1017.

Májeková M, Bello F, Dolezal J, Leps J. 2014. Plant functional traits as determinants of population stability. Ecology 95: 2369-2374.

Malysz M, Overbeck GE. 2018. Distinct tree regeneration patterns in Araucaria forest and old monoculture tree plantations. Brazilian Journal of Botany 41: 621-629.

Mandle L, Ticktin T. 2015. Changes in plant functional composition but no overall decline in functional diversity with moderate land use in a seasonally dry tropical ecosystem. Ecological Applications 24: 1117-1174.

Martín-Queller E, Diez JM, Ibáñez I, Saura S. 2013. Effects of silviculture on native tree species richness: interactions between management, landscape context and regional climate. Journal of Applied Ecology 50: 775-785.

Mason NWH, Lanoiselee C, Mouillot D, Irz P, Argillier C. 2007. Functional characters combined with null models reveal inconsistency in mechanisms of species turnover in lacustrine fish communities. Oecologia 153: 441-452.

Mason NWH, Mouillot D, Lee WG, Wilson JB. 2005. Functional richness, functional evenness and functional divergence: the primary components of functional diversity. Oikos 111: 112-118.

Medeiros JD, Savi M, Brito BFA. 2005. Seleção de áreas para a criação de Unidades de Conservação na Floresta Ombrófila Mista. Biotemas 18: 33-50.

Mendonça-Lima A, Duarte LS, Hartz SM. 2014. Comparing diversity and dispersal traits of tree communities in plantations and native forests in Southern Brazil. Natureza \& Conservação 12: 24-29.

Mouillot D, Mason NWH, Dumay O, Wilson JB. 2005. Functional regularity: a neglected aspect of functional diversity. Oecologia 142: 353-359.
Parrotta JA. 1995. Influence of overstorey composition on understory colonization by native species in plantations on a degraded tropical site. Journal of Vegetation Science 6: 627-636.

Parton W, Silver WL, Burke IC, et al. 2007. Global-Scale similarities in nitrogen release patterns during long-term decomposition. Science 19: 361-364.

Pérez-Harguindeguy N, Díaz S, Garnier E, Lavorel S, Poorter H, Jaureguiberry P. 2013. New handbook for standardised measurement of plant functional traits worldwide. Australian Journal of Botany 61: 167-234.

Podadera DS, Engel GL, Parrotta JA, Machado DL, Sato LM, Durigan G. 2015. Influence of removal of a non-native tree species Mimosa caesalpiniifolia Benth. on the regenerating plant communities in a tropical semideciduous forest under restoration in Brazil. Environmental Management 56: 1148-1158.

R Development Core Team. 2018. R: A language and environment for statistical computing. Vienna, R Foundation for Statistical Computing. https://www.R-project.org/

Raevel V, Violle C, Munoz F. 2012. Mechanisms of ecological succession: insights from plant functional strategies. Oikos 121: 1761-1770.

Rao CR. 1982. Diversity and dissimilarity coefficients: a unified approach. Theoretical Population Biology 21: 24-43.

Reich PB, Wright IJ, Cavender-Bares J, et al. 2003. The evolution of plant functional variation: Traits, spectra, and strategies. International Journal of Plant Sciences 164: 143-164.

Sanquetta CR, Mattel E. 2006. Perspectivas de recuperação e manejo sustentável das Florestas de Araucária. Curitiba, Multi-Graphic Gráfica e Editora.

Schneider CA, Rasband WS, Eliceiri KW. 2012. NIH Image to ImageJ: 25 years of image analysis. Nature Methods 9: 671-675.

Scholes MC, Nowicki TE. 1998. Effects of pines on soil properties and processes. Cambridge, Cambridge University Press.

SEMA - Secretaria de Meio Ambiente e Recursos Hídricos. 2013. Portaria SEMA n 79 de 31/10/2013. http://www.legisweb.com.br/ legislacao/?id $=261368$

Streit H, Carlucci MB, Bergamin RS, Pillar VD, Duarte LS. 2014. Patterns of diaspore functional diversity in Araucaria Forest successional stages in extreme southern Brazil. Revista Brasileira de Biociências 12: 106-114

Villéger S, Mason NWH, Mouillot D. 2008. New multidimensional functional diversity indices for a multifaceted framework in functional ecology. Ecology 89: 2290-2301.

Wang HF, Lencinas MV, Friedman CR, Zhu XZ, Qiu JX. 2012. Understory plant diversity assessment of Szemao pine (Pinus kesiya var. langbianensis) plantations in Yunnan, China. Collectanea Botanica 31: 51-65.

Weiher E, Clarke GDP, Keddy PA. 1998. Community assembly rules, morphological dispersion, and the coexistence of plant species. Oikos 81: 309-322.

Westoby M, Wright IJ. 2006. Land-plant ecology on the basis of functional traits. Trends in Ecology \& Evolution 21: 261-268.

Wright SJ. 2002. Plant diversity in tropical forests: a review of mechanisms of species coexistence. Oecologia 130: 1-14.

Zanchetta D, Diniz FV. 2006. Estudo da contaminação biológica por Pinus spp. em três diferentes áreas na estação Ecológica de Itirapina (SP, Brasil). Revista do Instituto Florestal 18: 1-14.

Zobel M. 1997. The relative role of species pools in determining plant species richness: An alternative explanation of species coexistence? Trends in Ecology \& Evolution 12: 266-269.

Zurita GA, Rey N, Varela DM, Villagra M, Bellocq MI. 2006. Conversion of the Atlantic Forest into native and exotic tree plantations. Effects on bird communities from the local and regional perspectives. Forest Ecology and Management 235: 164-173. 